Bul. Agrohorti 1 (4) : 18 - 25 (2013)

\title{
Pertumbuhan dan Produksi Padi Varietas Jatiluhur dan IR64 pada Sistem Budidaya Gogo dan Sawah
}

\section{Growth and Production of Rice IR64 and Jatiluhur Varieties on Lowland and Upland Culture Systems}

\author{
Andes Prayuda Yunanda,Ahmad Rifqi Fauzi, Ahmad Junaedi*
}

\author{
Departemen Agronomi dan Hortikultura, Fakultas Pertanian, Institut Pertanian Bogor \\ (Bogor Agricultural University), J1. Meranti, Kampus IPB Darmaga, Bogor 16680, Indonesia \\ Telp.\&Faks.62-251-8629353 e-mail agronipb@indo.net.id \\ *penulis untuk korespondensi: junaedi_agr@yahoo.com
}

Disetujui 24 Desember 2013/Published Online 10 Januari 2014

\begin{abstract}
The aim of this research was to determine the growth and production of two different rice varieties namely IR64 as lowland variety and Jatiluhur as upland variety that has been grown in the lowland and upland rice culture systems. This research was conducted from February to June 2012 in the green house of Sawah Baru Experimental Station, Bogor Agricultural University. This experiment used a splitplot design with three replications. Rice culture systems, namely lowland and upland systems were placed as main plot; whereas rice varieties, namely IR64 and Jatiluhur were placed as sub plot. Results showed that the treatment of cultivation system significantly affect the growth and production of rice. Treatment of varieties significantly affect the growth, but did not significantly affect on production. Interaction of culture systems and varieties generally affect the growth, but did not affect production of rice. This research showed that upland rice variety could achieve relatively as high as lowland rice variety under lowland culture system.
\end{abstract}

Keywords: lowland, rice varieties, upland, water scarcity

\section{ABSTRAK}

Tujuan dari penelitian ini adalah untuk mengetahui pertumbuhan dan produksi dari dua varietas padi yang berbeda, yaitu IR64 sebagai varietas padi sawah dan Jatiluhur sebagai varietas padi gogo yang dibudidayakan secara sawah dan gogo. Penelitian ini dilaksanakan dari bulan Februari hingga Juni 2012 di rumah plastik Kebun Percobaan Sawah Baru, Institut Pertanian Bogor. Penelitian ini menggunakan rancangan percobaan petak terbagi dengan tiga ulangan. Sistem budidaya yang digunakan yaitu sawah dan gogo yang ditempatkan sebagai petak utama; sedangkan varietas IR64 dan Jatiluhur ditempatkan sebagai anak petak. Hasil penelitian ini menunjukkan bahwa perlakuan sistem budidaya berpengaruh nyata terhadap pertumbuhan dan produksi padi. Perlakuan varietas berpengaruh nyata terhadap pertumbuhan padi, namun tidak berpengaruh nyata terhadap produksi. Interaksi perlakuan sistem budidaya dan varietas secara umum berpengaruh nyata terhadap pertumbuhan, namun tidak berpengaruh nyata terhadap produksi padi. Penelitian ini menunjukkan bahwa varietas padi gogo dapat ditanam secara budidaya sawah dengan hasil yang tidak berbeda dengan varietas padi sawah.

Kata kunci: gogo, kekurangan air, sawah, varietas padi

\section{PENDAHULUAN}

Tanaman padi merupakan tanaman pangan utama di Indonesia karena lebih dari setengah penduduk Indonesia menjadikan beras sebagai makanan pokok. Peningkatan jumlah penduduk Indonesia setiap tahunnya berdampak pada peningkatan kebutuhan pangan terutama beras. Oleh karena itu, masalah pangan dan ketahanan pangan di Indonesia tidak dapat dilepaskan dari komoditi beras (Nurmalina, 2007).

Berdasarkan Road MapPeningkatan Produksi Beras Nasional (P2BN) tahun 2012-2014 menuju surplus 10 juta ton beras pada tahun 2014, dengan sasaran produksi padi pada tahun 2013 sebesar 72.064 juta ton gabah kering giling (GKG). Produksi ini meningkat 4.239 juta ton $(6.25 \%)$ dari tahun 2012 sebesar 67.825 juta ton. Sasaran 
tersebut ditetapkan dengan perhitungan jumlah penduduk pada tahun 2013 sejumlah 248.334 juta jiwa dengan tingkat konsumsi beras sebesar 132.98 $\mathrm{kg}$ per kapita per tahun. Dengan sasaran produksi padi tersebut terjadi surplus beras sejumlah 7.49 juta ton (Deptan, 2013).

Salah satu varietas padi gogo yang sering dibudidayakan oleh masyarakat adalahvarietas Jatiluhur. Varietas ini memiliki potensi hasil tinggi yaitu mencapai 2.5-3.5 ton per hektar dengan tekstur nasi yang pera (Prasetyo, 1996). Varietas padi sawah yang sering dibudidayakan salah satunya adalah varietas IR64. Varietas ini memiliki tinggi batang $\pm 85 \mathrm{~cm}$, anakan produktif banyak dengan bobot 1000 butir \pm 27 g (Puslittan, 2013). Djunainah et al. (1993) menyatakan bahwa varietas IR64 sangat digemari oleh para petani dan konsumen karena rasa nasi enak, umur genjah (110-125 hari), dan potensi hasil yang tinggi yaitu mencapai 5 ton/ha. Varietas IR64 merupakan salah satu varietas padi sawah yang hemat dalam mengkonsumsi air. Konsumsi air bervariasi dengan kisaran 15.93-24.13 1/tanaman. Perbedaan ini disebabkan oleh adanya perbedaan morfologi maupun karakter fisiologi antar genotipe. Menurut Supijatno et al. (2012), varietas IR64 mengkonsumsi air sebesar $15.931 /$ tanaman dan konsumsi ini adalah yang terendah di antara varietas lain yang dicobakan, sementara itu Jatiluhur merupakan varietas yang paling banyak mengkonsumsi air tetapi hasil yang diperoleh juga banyak sehingga efisiensi penggunaan airnya tinggi sebesar $0.997 \mathrm{~g}$ gabah kering giling per liter air.

Padi dapat dibudidayakan dengan berbagai sistem budidaya. Menurut Taslim dan Fagi (1988), produksi yang dihasilkan pada berbagai budidaya padi yang dilakukan berbeda-beda jumlahnya. Budidaya padi gogo berpotensi untuk menghasilkan produksi sebesar 1-3 ton/ha, budidaya padi beririgasi dapat menghasilkan produksi 4-8 ton/ha, budidaya padi sawah tadah hujan dapat menghasilkan produksi 3-6 ton/ha, dan budidaya padi sawah pasang surut dapat menghasilkan produksi 1-4 ton/ha.

Sistem budidaya sawah membutuhkan air dalam jumlah sangat besar. Menurut Bouman et al. (2007), rata-rata pemakaian air untuk padi sawah mencapai $1300-1500 \mathrm{~mm}$ di mana $25-50 \%$ dari jumlah tersebut hilang akibat perkolasi dan perembesan.

Penurunan produksi bahan pangan nasional yang dirasakan saat ini lebih disebabkan oleh semakin sempitnya luas lahan pertanian yang produktif (terutama di Pulau Jawa) sebagai akibat alih fungsi seperti konversi lahan sawah, ditambah isu global tentang meningkatnya degradasi lahan (di negara berkembang) dan perubahan iklim yang tak menentu. Salah satu alternatif pilihan yang diharapkan dapat meningkatkan potensi produksi tanaman dalam rangka memenuhi kebutuhan pangan nasional adalah pendayagunaan lahan kering. Selain karena memang tersedia cukup luas, sebagian dari lahan kering belum diusahakan secara optimal sehingga memungkinkan peluang dalam pengembangannya.

Penelitian ini bertujuan mengetahui pertumbuhan dan produksi dua varietas padi yang berbeda yang ditanam pada sistem budidaya gogo dan sawah.

\section{BAHAN DAN METODE}

Penelitian ini dilaksanakan di Kebun Percobaan Sawah Baru, University Farm, dan Laboratorium Produksi Tanaman Departemen Agronomi dan Hortikultura, Institut Pertanian Bogor. Penelitian ini dilaksanakan pada bulan Februari-Juni 2012.

Bahan tanam yang digunakan adalah dua varietas padi, yaitu varietas IR64 dan Jatiluhur. Pupuk yang digunakan adalah Urea, SP-18 dan $\mathrm{KCl}$ dengan dosis sesuai rekomendasi yaitu masing-masing sebanyak 250, 200, dan $100 \mathrm{~kg}$ per hektar.

Alat yang digunakan yaitu alat-alat pertanian, oven, dan alat-alat ukur berupa penggaris dan timbangan analitik.

\section{Persiapan Rumah Plastik dan Petak Tanam}

Percobaan dilakukan di dalam rumah plastik yang berukuran $30 \mathrm{~m} \times 12 \mathrm{~m}$, dengan tinggi $\pm 2.2-4.5 \mathrm{~m}$. Rumah plastik terdiri atas bambu sebagai tiang/kerangka, jaring plastik sebagai dinding, dan plastik transparan sebagai atap. Unit percobaan terdiri atas petakan berukuran $3 \mathrm{~m} \times 3 \mathrm{~m}$ yang dilengkapi dengan pipa irigasi yang terhubung ke reservoir (kolam penampungan air). Jarak antar petak yang digunakan adalah 35 $\mathrm{cm}$ dengan pengerasan semen sebagai pembatas.

Percobaan yang dilakukan meliputi dua faktor dan menggunakan rancangan petak terbagi (splitplot) dengan tiga ulangan. Faktor pertama adalah sistem budidaya yang ditempatkan sebagai petak utama, sedangkan faktor kedua adalah varietas padi yang ditempatkan sebagai anak petak. Sistem budidaya terdiri atas dua sistem, yaitu sistem budidaya sawah (T1) dan gogo (T2). 
Varietas padi yang digunakan yaitu IR64 (V1) dan Jatiluhur (V2). Dari dua faktor tersebut diperoleh 4 kombinasi yang masing-masing diulang sebanyak 3 ulangan, sehingga diperoleh 12 satuan percobaan.

Model linier aditif rancangan perlakuan penelitian ini dapat ditulis sebagai berikut (Gomez dan Gomez 1995).

$$
Y_{i j k}=\mu+\alpha_{i}+\theta_{i k}+\beta_{j}+(\alpha \beta)_{i j}+\varepsilon_{i j k}
$$

\section{Keterangan:}

$$
\begin{aligned}
& \mathrm{i}=\text { Sistem budidaya padi ke 1,2 } \\
& \mathrm{j}=\text { Varietas padi ke 1,2 } \\
& \mathrm{Y}_{\mathrm{ijk}}=\text { Nilai pengamatan perlakuan sistem } \\
& \mu \quad=\text { Rataan umum } \\
& \alpha_{\mathrm{i}} \quad=\text { Pengaruh perlakuan sistem budidaya } \\
& \beta_{\mathrm{j}}=\text { Pengaruh perlakuan varietas padi } \mathrm{ke}- \\
& \mathrm{j} \\
& (\alpha \beta)_{\mathrm{i}}=\text { Interaksi perlakuan sistem budidaya } \\
& \text { padi ke-i dengan varietas ke-j } \\
& \theta \mathrm{ik}=\text { Galat petak utama } \\
& \varepsilon_{\mathrm{ijk}}=\text { Galat anak petak }
\end{aligned}
$$

Pengolahan tanah awal pada sistem budidaya sawah dilakukan dengan penggenangan tanah selama 5 hari, dilanjutkan dengan pelumpuran sebanyak 2 kali dengan cara dicangkul, dan perataan tanah pada tahap akhir. Pengolahan tanah awal pada sistem budidaya gogo dilakukan dengan penggemburan tanah dan penyiraman air sebanyak $601 /$ hari per petak tanam selama 5 hari berturut-turut. Pemberian air ini setara dengan curah hujan $200 \mathrm{~mm} / \mathrm{bulan}$.

\section{Persiapan Benih dan Penanaman}

Pertama-tama masing-masing benih untuk setiap petak tanam ditimbang sebanyak $35 \mathrm{~g}$ dan dioven selama 72 jam pada suhu $43^{\circ} \mathrm{C}$. Hal ini bertujuan mematahkan dormansi dan menyeragamkan daya berkecambah benih. Selanjutnya benih direndam selama 12 jam, benih yang terapung dibuang, kemudian benih ditiriskan dan siap ditanam. Untuk Sistem budidaya sawah, benih disemai di lapangan hingga bibit berumur 12 hari lalu dilakukan transplanting ke petakan sebanyak 1 bibit per lubang tanam, sedangkan untuk sistem budidaya gogo benih ditanam langsung pada hari ke-6 setelah pengolahan tanah. Penanaman dilakukan dengan cara penugalan lalu ditanam 5 benih per lubang. Jarak tanam yang digunakan yaitu $25 \mathrm{~cm} \times 20 \mathrm{~cm}$. Populasi tanaman pada setiap petak tanam berjumlah 180 tanaman.

\section{Pemeliharaan}

Pemupukan tanaman dilakukan dalam tiga tahap. Pemupukan pertama diberikan pada $1 \mathrm{MST}$ menggunakan $33.75 \mathrm{~g} \mathrm{~N}$ (1/3 dosis), $32.4 \mathrm{~g} \mathrm{P}_{2} \mathrm{O}_{5}$, dan $54 \mathrm{~g} \mathrm{~K}_{2} \mathrm{O}$ per petak tanam. Pemupukan kedua dan ketiga diberikan pada 5 dan 9 MST menggunakan $33.75 \mathrm{~g} \mathrm{~N}$ per petak tanam. Pengairan tanaman pada sistem budidaya gogo dilakukan dengan penyiraman langsung sebanyak \pm 60 l/hari per petak tanam, sedangkan pengairan pada sistem budidaya sawah, air dibiarkan terus mengalir ke dalam petak melalui pipa irigasi. Permukaan air dipertahankan setinggi $5 \mathrm{~cm}$ dari permukaan tanah.Pengendalian gulma dilakukan dengan cara manual, yaitu dengan cara mencabut gulma-gulma yang tumbuh di antara tanaman. Pengendalian hama, dan penyakit dijelaskan pada bab berikutnya.

\section{Analisis Data}

Pengamatan dilakukan dengan mengamati 5 tanaman sampel pada setiap petak perlakuan yang dipilih secara acak. Adapun peubah yang diamati pada penelitian ini antara lain:

1. Tinggi tanaman $(\mathrm{cm})$, diukur dari permukaan tanah hingga ujung daun yang tertinggi. Pengamatan dilakukan setiap minggu sejak 210 MST

2. Jumlah anakan, dihitung di dalam tiap rumpun setiap minggu sejak 2-10 MST.

3. Panjang dan lebar daun bendera $(\mathrm{cm})$, panjang daun diukur dari pangkal daun hingga ujung daun bendera, sedangkan lebar daun diukur dengan mengukur bagian daun bendera terlebar.

4. Jumlah malai per rumpun, dihitung saat panen.

5. Panjang malai $(\mathrm{cm})$, diukur dari dasar malai hingga ujung malai.

6. Jumlah gabah isi per rumpun (butir).

7. Persentase gabah isi (\%).

8. Jumlah gabah hampa (butir).

9. Bobot gabah pe rumpun (g), dihitung dengan menimbang total gabah dalam satu rumpun dengan kadar air $14 \%$.

10. Bobot 1000 butir gabah (g), dihitung dengan menimbang 1000 butir gabah isi.

Pengolahan data dilakukan dengan menggunakan sidik ragam pada selang kepercayaan $95 \%$. 


\section{HASIL DAN PEMBAHASAN}

\section{Pertumbuhan Vegetatif}

Faktor tunggal perlakuan sistem budidaya pada umur tanaman 5-10 MST berpengaruh nyata terhadap tinggi tanaman. Hal ini tersaji pada Gambar 1.a. Sistem budidaya sawah menghasilkan tanaman yang lebih tinggi dibandingkan sistem budidaya gogo. Terlihat dari tinggi tanaman di akhir pengamatan pada sistem budidaya sawah dan gogo yaitu masing-masing setinggi 122.06 dan $85.23 \mathrm{~cm}$. Menurut Manurung (2002), secara umum kondisi anaerob mampu meningkatkan ratarata tinggi tanaman padi varietas Jatiluhur dan IR64.

Gambar 1.b menunjukkan pertumbuhan tinggi tanaman varietas IR64 dan Jatiluhur. Faktor tunggal perlakuan varietas berpengaruh nyata terhadap tinggi tanaman pada umur tanaman 5-10
MST. Varietas Jatiluhur menghasilkan tanaman yang lebih tinggi dibandingkan varietas IR64. Hal ini terlihat dari tinggi tanaman varietas IR64 dan Jatiluhur di akhir pengamatan, yaitu masingmasing sebesar 90.00 dan $117.29 \mathrm{~cm}$. Menurut Manurung (2002), varietas Jatiluhur memiliki tanaman yang lebih tinggi dibandingkan varietas IR64 baik pada kondisi aerob maupun anaerob. Sementara itu menurut Farooq et al. (2010), varietas IR64 menghasilkan tinggi maksimum pada saat diairi secara teratur dibandingkan pada kondisi kekeringan (gogo).

Interaksi perlakuan sistem budidaya dan varietas berpengaruh nyata terhadap tinggi tanaman pada 10 MST. Berdasarkan Tabel 1, tanaman tertinggi dihasilkan oleh padi varietas Jatiluhur yang ditanam pada sistem budidaya sawah, sedangkan tanaman terendah dihasilkan oleh varietas IR64 yang ditanam pada sistem budidaya gogo. Keragaan tinggi tanaman pada masing-masing perlakuan tersaji pada Gambar 2.

\section{ฮ્త్}
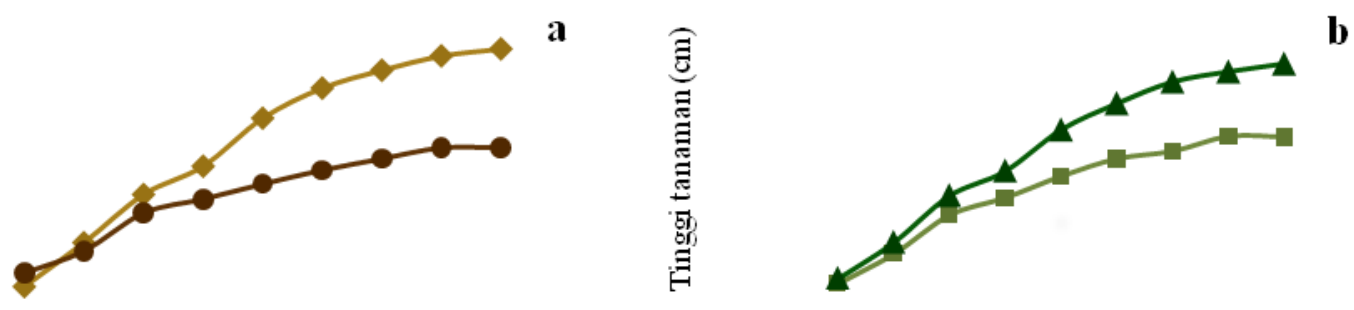

\section{b}

Umur tanaman (MST)

\section{Umur tanaman (MST)}

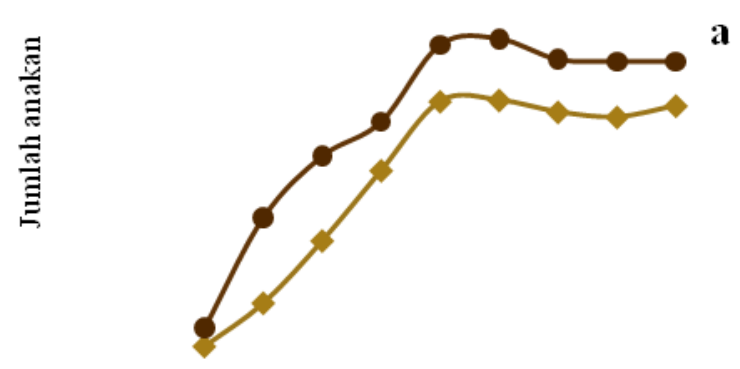

Umur tanaman (MST)

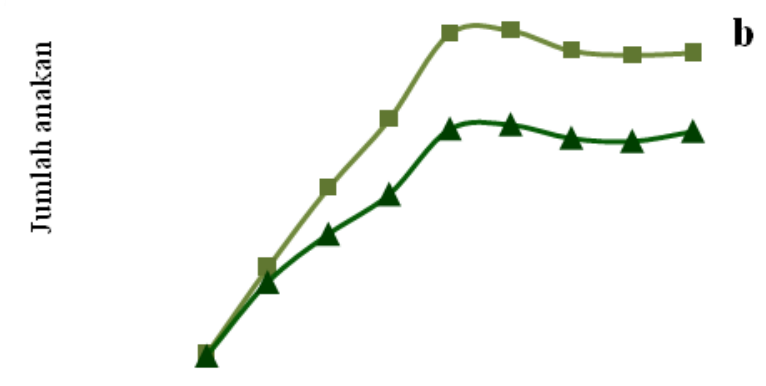

Umur tanaman (MST)

Keterangan: Sistem budidaya sawah ( $\diamond$ ), sistem budidaya gogo ( Ovarietas IR64 ( ), , an varietas Jatiluhur ( ).

Gambar 1.Tinggi tanaman dan jumlah anakan per rumpun pada perlakuan sistem budidaya (a) dan varietas (b) 
Tabel 1.Tinggi tanaman dan jumlah anakan per rumpun varietas IR64 dan Jatiluhur pada sistem budidaya gogo dan sawah

\begin{tabular}{|c|c|c|c|}
\hline Peubah & IR64 & & iluhur \\
\hline \multicolumn{4}{|c|}{ Tinggi tanaman $(\mathrm{cm})$} \\
\hline Sistem budidaya sawah & $102.13 b$ & 141.97 & $\mathrm{a}$ \\
\hline Sistem budidaya gogo & $77.80 \mathrm{c}$ & 92.63 & $\mathrm{bc}$ \\
\hline \multicolumn{4}{|c|}{ Jumlah anakan } \\
\hline Sistem budidaya sawah & $10.67 \mathrm{p}$ & 5.70 & $\mathrm{q}$ \\
\hline Sistem budidaya gogo & $9.73 \mathrm{p}$ & 9.60 & $\mathrm{p}$ \\
\hline
\end{tabular}

Keterangan: Angka yang diikuti huruf yang berbeda pada masing-masing peubah berbeda nyata pada taraf $5 \%$ berdasarkan uji DMRT.
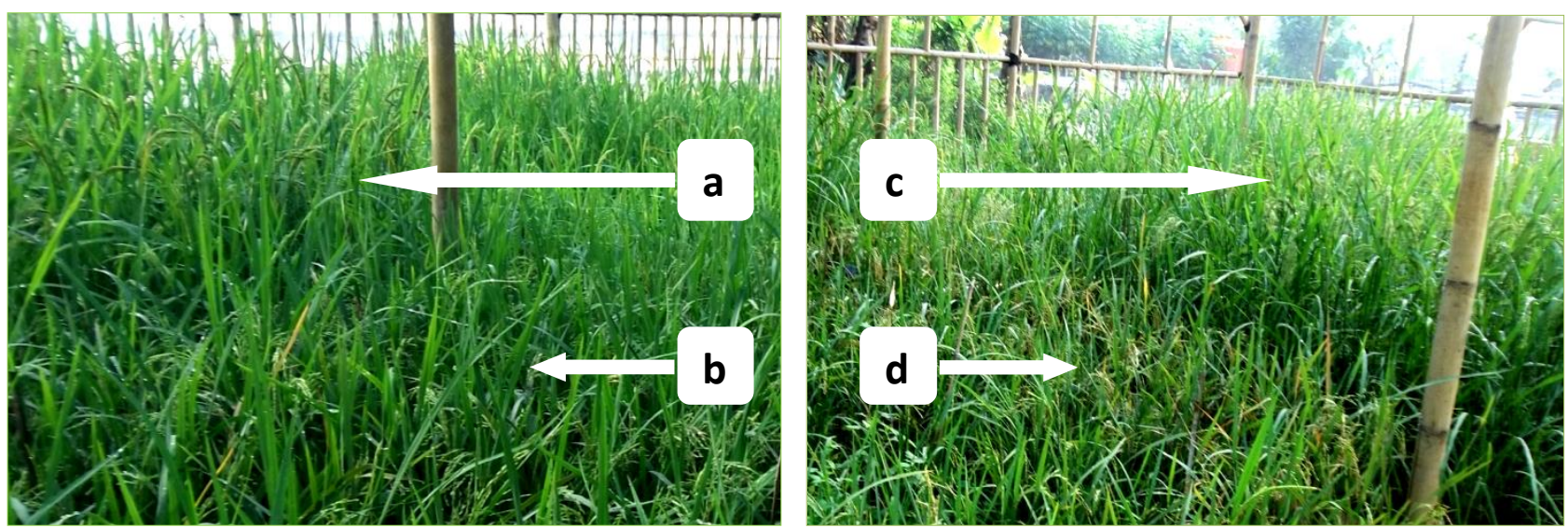

Keterangan: T1 = Sistem budidaya sawah, T2 = Sistem budidaya gogo, V1 = Varietas IR64, dan V2 = Varietas Jatilhur.

Gambar 2Keragaan tinggi tanaman padi T1V2 (a), T1V1 (b), T2V2 (c), dan T2V1 (d) pada 10 MST

Pada Gambar 1.a menunjukkan faktor tunggal perlakuan sistem budidaya berpengaruh nyata terhadap jumlah anakan per rumpun padi pada tiap MST kecuali pada 5, 6, 7 dan 9 MST. Pada akhir pengamatan (10 MST), sistem budidaya gogo menghasilkan 10 anakan per rumpun, lebih banyak dibandingkan jumlah anakan padi pada sistem budidaya sawah yaitu 8 anakan per rumpun. Pada 8 dan 9 MST jumlah anakan padi sistem budidaya gogo dan sawah mengalami sedikit penurunan. Hal ini disebabkan oleh adanya kerebahan tanaman dan kematian anakan.

Faktor tunggal perlakuan varietas tidak berpengaruh nyata terhadap jumlah anakan per rumpun pada dua minggu petama, dan berpengaruh nyata pada minggu berikutnya. Hal ini tersaji pada Gambar 1.b. Pada minggu terakhir (10 MST), varietas IR64 menghasilkan jumlah anakan yang lebih banyak dibandingkan varietas Jatiluhur, yaitu masing-masing sebanyak 10 dan 8 anakan per rumpun. Varietas padi modern memiliki jumlah anakan yang tinggi, setiap rumpun yang ditanam 3-5 bibit pada kondisi lingkungan tumbuh yang sesuai akan menghasilkan 30-40 anakan. Dari jumlah anakan tersebut, hanya sekitar 20 anakan yang menghasilkan malai (anakan produktif) (Peng 1994). Dari data yang diperoleh, jumlah anakan maksimal yang dihasilkan masing-masing varietas hanya mencapai \pm 10 anakan. Pada 8 dan 9 MST jumlah anakan varietas IR64 dan Jatiluhur mengalami penurunan. Penurunan jumlah anakan disebabkan oleh faktor yang sama pada perlakuan sistem budidaya, yaitu oleh adanya kerebahan tanaman dan kematian anakan.

Interaksi perlakuan sistem budidaya dan varietas berpengaruh nyata terhadap jumlah anakan per rumpun pada 9 dan 10 MST. Jumlah anakan per rumpun terendah dihasilkan oleh varietas Jatiluhur yang ditanam pada sistem budidaya sawah. Varietas Jatiluhur yang ditanam pada sistem budidaya gogo dan IR64 pada sawah maupun pada gogo, menghasilkan anakan per rumpun yang banyak. Hal ini tersaji pada Tabel 1 . Jumlah anakan juga menentukan tingkat kekuatan tanaman terhadap kerebahan. Jumlah anakan yang sedikit dan tinggi tanaman yang tinggi pada varietas Jatiluhur yang ditanam pada sistem 
budidaya sawah, mengakibatkan besarnya jumlah kerebahan tanaman.

Menurut Abdullah et al. (2008), jumlah anakan per rumpun yang terlalu banyak mengakibatkan masa masak malai tidak serempak, sehingga menurunkan produktivitas dan atau mutu beras. Namun jika jumlah anakan sedikit, bila ada serangan hama yang mengakibatkan kerusakan anakan, akan menurunkan hasil.

Tabel 2.Panjang dan lebar daun bendera

\begin{tabular}{|c|c|c|}
\hline Perlakuan & Panjang daun $(\mathrm{cm})$ & Lebar daun $(\mathrm{cm})$ \\
\hline \multicolumn{3}{|c|}{ Sistem budidaya } \\
\hline Sawah & $46.37 \mathrm{a}$ & 1.07 \\
\hline Gogo & $34.28 \mathrm{~b}$ & 0.94 \\
\hline \multicolumn{3}{|l|}{ Varietas } \\
\hline IR64 & $35.84 q$ & $0.90 \mathrm{q}$ \\
\hline Jatiluhur & $44.81 \mathrm{p}$ & $1.11 \mathrm{p}$ \\
\hline
\end{tabular}

Keterangan : Angka yang diikuti huruf yang berbeda pada masing-masing faktor perlakuan berbeda nyata pada taraf $5 \%$ berdasarkan uji DMRT.

Daun kelopak yang terpanjang dan membalut ruas paling atas disebut daun bendera. Tepat pada posisi daun pelepah teratas yang menjadi lidah daun dan daun bendera muncul ruas yang akan menjadi bulir padi (Siregar 1981). Faktor tunggal perlakuan sistem budidaya hanya berpengaruh nyata terhadap panjang dan tidak berpengaruh nyata terhadap lebar daun bendera. Perlakuan sistem budidaya sawah menghasilkan daun bendera yang lebih panjang dibandingkan sistem budidaya gogo, yaitu masing-masing sebesar 46.37 dan $34.28 \mathrm{~cm}$ (Tabel 2).

Pada Tabel 2 menunjukkan faktor tunggal perlakuan varietas berpengaruh nyata terhadap panjang dan lebar daun bendera. Daun bendera yang dihasilkan oleh varietas Jatiluhur lebih panjang dan lebih lebar dibandingkan varietas IR64. Panjang daun bendera pada varietas Jatiluhur dan IR64 masing-masing sebesar 44.81 dan 35.84 $\mathrm{cm}$, dengan lebar masing-masing sebesar 1.11 dan $0.90 \mathrm{~cm}$.

\section{Komponen Hasil dan Hasil}

Potensi hasil padi ditentukan oleh komponen hasil, yaitu jumlah malai per rumpun, jumlah gabah per malai, persentase gabah isi, dan bobot gabah bernas (Abdullah et al. 2008). Menurut Tubur et al. (2012), perlakuan kekeringan dan genotipe berpengaruh nyata terhadap jumlah malai per rumpun, persen pembungaan, panjang malai, persen gabah hampa, bobot gabah per rumpun, bobot 1000 butir, bobot basah tajuk, bobot kering tajuk dan indeks panen.

Tabel 3.Jumlah dan panjang malai

\begin{tabular}{lcc}
\hline \multicolumn{1}{c}{ Perlakuan } & Jumlah malai rumpun $^{-1}$ & Panjang malai (cm) \\
\hline Sistem budidaya & & \\
Sawah & $7.13 \mathrm{a}$ & 26.70 \\
Gogo & $3.92 \mathrm{~b}$ & 23.00 \\
\hline Varietas & & \\
IR64 & $7.87 \mathrm{p}$ & 26.42 \\
Jatiluhur & $3.18 \mathrm{q}$ & 23.29 \\
\hline
\end{tabular}

Keterangan : Angka yang diikuti huruf yang berbeda pada masing-masing faktor perlakuan berbeda nyata pada taraf $5 \%$ berdasarkan uji DMRT.

Malai muncul pertama kali pada saat tanaman berumur 10 MST. Pada saat panen (13 MST), faktor tunggal perlakuan sistem budidaya berpengaruh nyata terhadap jumlah malai per rumpun. Sistem budidaya sawah menghasilkan 7 malai per rumpun, lebih besar dibandingkan sistem budidaya gogo yaitu 4 malai per rumpun. Hal ini tersaji pada Tabel 3.

Faktor tunggal perlakuan varietas berpengaruh nyata terhadap jumlah malai per rumpun pada saat panen. Varietas IR64 menghasilkan 8 malai per rumpun, lebih banyak 
dibandingkan varietas Jatiluhur, yaitu hanya 3 malai per rumpun.

Panjang malai diukur saat panen, yaitu dengan mengukur malai dari ruas pertama hingga ujung malai. Faktor tunggal perlakuan sistem budidaya dan varietas tidak berpengaruh nyata terhadap panjang malai. Hal ini tersaji pada Tabel 3. Menurut hasil penelitian Tubur et al. (2012), pengaruh kekeringan nyata menghambat perkembangan malai pada sistem budidaya sawah dan gogo.

Tabel 4.Komponen hasil dan hasil

\begin{tabular}{lccccc}
\hline \multicolumn{1}{c}{ Perlakuan } & $\begin{array}{c}\text { Jumlah gabah isi }^{-1} \\
\text { rumpun }^{-1} \text { (butir) }\end{array}$ & $\begin{array}{c}\text { Persentase } \\
\text { gabah isi (\%) }\end{array}$ & $\begin{array}{c}\text { Jumlah gabah } \\
\text { hampa rumpun } \\
\text { (butir) }\end{array}$ & $\begin{array}{c}\text { Bobot gabah } \\
\text { rumpun }^{-1}(\mathrm{~g})\end{array}$ & $\begin{array}{c}\text { Bobot } \\
1 \text { 000 butir } \\
(\mathrm{g})\end{array}$ \\
\hline Sistem budidaya & & & & & \\
Sawah & $569.60 \mathrm{a}$ & 72.13 & 72.68 & $13.35 \mathrm{a}$ & $22.35 \mathrm{a}$ \\
Gogo & $108.23 \mathrm{~b}$ & 66.62 & 48.89 & $4.34 \mathrm{~b}$ & $17.37 \mathrm{~b}$ \\
\hline Varietas & & & & & \\
IR64 & $281.93 \mathrm{q}$ & 66.94 & 47.21 & 8.19 & 20.32 \\
Jatiluhur & $395.90 \mathrm{p}$ & 71.81 & 74.36 & 9.49 & 19.40 \\
\hline
\end{tabular}

Keterangan : Angka yang diikuti huruf yang berbeda pada masing-masing faktor perlakuan berbeda nyata pada taraf $5 \%$ berdasarkan uji DMRT.

Faktor tunggal perlakuan sistem budidaya sawah dan gogo berpengaruh nyata terhadap jumlah gabah isi, bobot gabah per rumpun, dan bobot 1000 butir gabah, namun tidak berpengaruh nyata terhadap persentase gabah isi dan jumlah gabah hampa per rumpun. Interaksi perlakuan sistem budidaya dan varietas tidak berpengaruh nyata terhadap hasil dan komponen hasil. Hal ini tersaji pada Tabel 4. Tubur et al. (2012) menyatakan bahwa sistem lahan kering nyata menurunkan tinggi tanaman, jumlah anakan, panjang malai, bobot 1000 butir, serta meningkatkan persentase jumlah gabah hampa, namun interaksi kekeringan dan varietas tidak berpengaruh nyata.

Sistem budidaya sawah menghasilkan jumlah gabah isi per rumpun lebih banyak dibandingkan gogo. Terlihat dari hasil panen sistem budidaya sawah dan gogo menghasilkan jumlah gabah isi per rumpun masing-masing sebanyak 570 dan 108 butir. Rendahnya jumlah gabah isi karena tingginya jumlah gabah hampa. Kehampaan gabah disebabkan oleh hama walang sangit yang menghisap pati gabah pada fase pengisian gabah.

Jennings et al. (1979) menyatakan bahwa persentase gabah isi merupakan pembagian jumlah gabah isi dibagi jumlah gabah total. Gabah isi merupakan karakter yang sangat mempengaruhi potensi hasil. Sistem budidaya sawah menghasilkan bobot gabah per rumpun lebih besar dibandingkan sistem budidaya gogo, yaitu masingmasing sebesar 13.35 dan $4.34 \mathrm{~g}$. Sistem budidaya sawah menghasilkan bobot 1000 butir gabah lebih besar dibandingkan sistem budidaya gogo, yaitu masing-masing sebesar 22.35 dan $17.37 \mathrm{~g}$.

Faktor tunggal perlakuan varietas IR64 dan Jatiluhur berpengaruh nyata terhadap jumlah gabah isi per rumpun, namun tidak berpengaruh nyata terhadap persentase gabah isi, jumlah gabah hampa per rumpun, bobot gabah per rumpun, dan bobot 1000 butir gabah.

Varietas Jatiluhur menghasilkan jumlah gabah isi per rumpun yang lebih banyak dibandingkan varietas IR64, yaitu masing-masing sebesar 396 dan 282 butir.

Tabel 5.Bobot gabah per rumpun

\begin{tabular}{lrrr}
\hline & \multirow{2}{*}{ Sistem budidaya } & IR64 & Jatiluhur \\
\cline { 2 - 3 } & \multicolumn{2}{c}{$\left(\right.$ g rumpun $\left.^{-1}\right)$} \\
\hline Sawah & 12.53 & 14.16 \\
Gogo & 3.86 & 4.82 \\
\hline
\end{tabular}

Berdasarkan nilai rata-rata bobot gabah per rumpun pada Tabel 5, varietas Jatiluhur yang ditanam pada sistem budidaya sawah menghasilkan bobot gabah per rumpun yang tertinggi yaitu sebesar $14.16 \mathrm{~g}$, sedangkan varietas IR64 yang ditanam pada sistem budidaya gogo 
mengasilkan bobot gabah per rumpun yang terendah yaitu hanya sebesar $3.86 \mathrm{~g}$.

Menurut Taslim dan Fagi (1988), budidaya padi sawah dapat menghasilkan produksi 4-8 ton/ha, sedangkan budidaya padi gogo berpotensi menghasilkan produksi sebesar 1-3 ton/ha. Suprihatno et al. (2009) menyatakan bahwa IR64 berpotensi menghasilkan produksi 5.0 ton/ha, sedangkan varietas Jatiluhur berpotensi menghasilkan produksi sebesar 3.5 ton/ha. Perkiraan produktivitas padi pada sistem budidaya sawah dan gogo pada penelitian ini masing-masing sebesar dan 2.670 dan 0.868 ton/ha, sedangkan varietas IR64 dan Jatiluhur masing-masing menghasilkan 1.639 dan 1.898 ton/ha. Rendahnya produktivitas disebabkan oleh pasokan air yang terhambat, serangan hama penyakit, dan kerebahan.

\section{KESIMPULAN}

Hasil penelitian ini menunjukkan bahwa perlakuan sistem budidaya berpengaruh nyata terhadap pertumbuhan dan produksi padi. Perlakuan varietas berpengaruh nyata terhadap pertumbuhan padi, namun tidak berpengaruh nyata terhadap produksi. Sistem budidaya sawah menghasilkan produktivitas yang lebih tinggi dibandingkan sistem budidaya gogo yaitu mencapai hingga tiga kali lebih tinggi dibandingkan sistem budidaya gogo.

\section{DAFTAR PUSTAKA}

Abdullah B, Tjokrowidjojo S, Sularjo. 2008. Perkembangan dan prospek perakitan padi tipe baru di Indonesia. J Litbang Pertanian. 27:1-9.

Bouman BAM, Humphreys E, Tuong TP, Barker R. 2007. Rice and water. Advances in Agronomy. 92:187-237.

[Deptan] Departemen Pertanian. 2013. Sasaran produksi padi 2013 menuju surplus beras 10 juta ton. [diacu 2013 Januari 30]. Tersedia dari: http://www.deptan.go.id.

Djunainah, Suwanto TW, Husni K. 1993. Deskripsi Varietas Unggul Padi. Jakarta (ID): Pusat Penelitian dan Pengembangan Tanaman Pangan.

Farooq M, Kobayashi N, Wahid A, Ito O, Basra SMA. 2009. Strategies for producing more rice with less water. Advances in Agronomy. 101:351-388.
Gomez KA, Gomez AA. 1995. Prosedur Statistika untuk Penelitian Pertanian. Sjamsudian, Baharsjah JS, penerjemah. Jakarta (ID): Universitas Indonesia. Terjemahan dari: Statistical Procedures for Agriculture Research.

Jennings PR, Coffman WR, Kauffman HE. 1979. Rice Improvement. Los Banos (PH): International Rice Research Institute.

Manurung H. 2002. Respon fisiologis beberapa varietas padi (Oryza sativa L.) pada lahan tergenang (anaerob) dan lahan tidak tergenang (aerob) [tesis]. Bogor (ID): Institut Pertanian Bogor.

Nurmalina R. 2007. Model ketersediaan beras yang berkelanjutan untuk mendukung ketahanan pangan nasional [disertasi]. Bogor (ID): Institut Pertanian Bogor.

Peng S. 1994. Evaluation of the new plant ideotype for increased yield potential. p 5-20. Di dalam: Cassman $\mathrm{KG}$, editor. Breaking The Yield Barrier. Los Banos (PH): International Rice Research Institute.

Prasetyo YT. 1996. Bertanaman Padi Gogo tanpa Olah Tanah. Ungaran (ID): Penebar Swadaya.

[Puslittan] Pusat Penelitian dan Pengembangan Tanaman Pangan. 2013. Deskripsi padi varietas IR64. [diacu 2013 Januari 30]. Tersedia dari: http://www.puslittan.bogor.net.

Siregar H. 1981. Budidaya Tanaman Padi di Indonesia. Jakarta (ID): Sastra Hudaya.

Supijatno, Chozin MA, Soepandi D, Lubis I, Junaedi A, Trikoesoemaningtyas. 2012. Evaluasi konsumsi air genotipe padi untuk potensi efisiensi penggunaan air. J Agron Indonesia. 40(1):15-20.

Suprihatno B, Daradjat AA, Satoto, Baehaki SE, Widiarta IN, Setyono A, Indrasari SD, Lesmana OS, Sembiring H. 2009. Deskripsi Varietas Padi. Jakarta (ID): Badan Penelitian dan Pengembangan Tanaman Pangan.

Taslim H, Fagi AM. 1988. Ragam budidaya padi. Di dalam:Ismunadji M, Partohardjono S, Syam M, Widjono A, editor. Padi Buku 1. Bogor (ID): Badan Penelitian dan Pengembangan Tanaman Pangan Bogor.

Tubur HW, Chozin MA, Santosa E, Junaedi A. 2012. Respon agronomi varietas padi terhadap periode kekeringan pada sistem sawah. $J$ Agron Indonesia. 40(3):167-173. 